\title{
THE PREPARATION OF YOUNG BIATHLETES IN THE ANNUAL CYCLE
}

\section{Konstantin Dunayev, Sergey Seyranov}

Abstract. The paper discusses issues related to the volume of training load on the basic cyclic training facility in a year cycle of preparation in young biathletes. For of the total amount of the cyclic load as a monthly, and for periods of training. This article is intended for coaches, students and teachers of educational institutions of physical culture.

Keywords: periods of training, training tools, volume, intensity.

Introduction. The planning of the volume of the training loads, selection and distribution of the main training facilities, the ratio of types of training at different microcycles, mesocycles, macrocycles affect dramatically the quality of training of athletes, where the main goal is successful performance at the main competitions of the season. For the national team and the youth team of Russia it is participating in the World and Europe Championships. It is important to bring the athletes to the competitions in the best shape[1,4,5].

The purpose of the study is to identify the possibilities of improvement of sports and technical performance of athletes 18-19 years, through the rational construction of training process on the distribution of cyclic loads in the annual cycle of training.

\section{Objectives of the study:}

1. To develop the amount of cyclic exercise facilities at the biathlon 18-19 years in the annual cycle of training.

2. To determine the effectiveness of the developed technique training of athletes 18-19 years (results presented at important competitions).

The results of the study and their discussion. The achievement of high sports-technical results in biathlon depends on basic training, laying the foundation while training at a young age. And here a special role is played by the decision of the planning volume and intensity of training loads, selection and distribution of the basic means of training the ratio of types of training at different microcycles, mesocycles, and macrocycles. The quality of training of athletes depends mostly on it, where the main goal is successful performance at the main competitions of the season $[2.3,6]$.

It is essential to bring the athletes to the competitions in the best shape $[6,7$, and 8$]$.

Well-written training plan for different stages of the annual cycle of preparation depends on the theoretical knowledge of the trainer, his experience in competition and its practice with the team (work experience).

Typical, a standard macrocycle used in the planning of the training load, developed for four years. The basis is the time between Olympic Games. The planning takes place over the years. At the end of each year the correction is made in the training process for such parameters as volume and intensity made on the basis of criteria of physical condition, and to a greater extent, the results of the main starts of the season. In addition, power tools training and the methods of use for the development of motor skills are reviewed.

Gradual increase in training loads throughout the annual cycle and in training all next years is planned in the training of young men, while the biathlon is not achieved the training parameters in adult sportsmen.

This article examines the implementation of training and cyclic loading of national team on biathlon of 18-19years old in Moscow region for two years of training.

In tables 1,2 there are key parameters of the training and cyclic loading in the annual cycle of training. 
Table 1

The main parameters of the training and cyclic loading in the annual cycle of training 2015-2016

\begin{tabular}{|c|c|c|c|c|c|c|c|c|c|c|c|c|c|}
\hline & 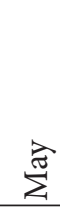 & $\stackrel{\Xi}{\Xi}$ & $\underline{\Xi}$ & 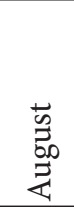 & 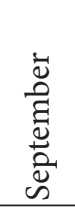 & $\begin{array}{l}\dot{\Xi} \\
\stackrel{0}{0} \\
\dot{U} \\
0\end{array}$ & $\begin{array}{l}\dot{\nu} \\
\text { है } \\
\text { ठे } \\
\text { zे }\end{array}$ & 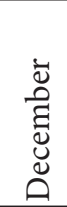 & 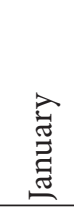 & 氞 & 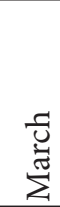 & $\overline{\bar{z}}$ & 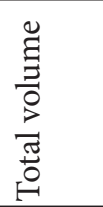 \\
\hline Rollers,km & & 219 & 226 & 409 & 258 & & & & & & & & 1112 \\
\hline Cross,km & 86 & 179 & 96 & 186 & 130 & 38 & 52 & 35 & 75 & 40 & 45 & 85 & 1047 \\
\hline Bike,km & 56 & 60 & & & & & & & & & & & 116 \\
\hline Skiing,km & & & & & & 247 & 430 & 246 & 432 & 309 & 301 & & 1965 \\
\hline TOTAL km & 142 & 458 & 322 & 595 & 388 & 285 & 482 & 284 & $\mathbf{5 0 7}$ & 349 & 346 & 85 & 4230 \\
\hline
\end{tabular}

Table 2

The main parameters of the training and cyclic loading in the annual cycle of preparation, 2016/2017.

\begin{tabular}{|c|c|c|c|c|c|c|c|c|c|c|c|c|c|}
\hline & $\sum^{\mathrm{a}}$ & $\Xi$ & 촐 & 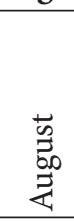 & 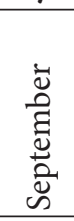 & $\begin{array}{l}\dot{\Delta} \\
0 \\
0 \\
\dot{U}\end{array}$ & $\begin{array}{l}\dot{\bar{\nu}} \\
\tilde{\Xi} \\
\tilde{0} \\
\tilde{z} \\
\end{array}$ & 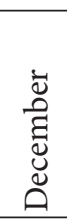 & $\begin{array}{l}\text { 悹 } \\
\text { 芯 } \\
\end{array}$ & 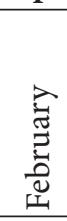 & $\begin{array}{l}\overrightarrow{0} \\
\stackrel{0}{\pi} \\
\end{array}$ & $\begin{array}{l}\overrightarrow{\bar{z}} \\
\text { 安 }\end{array}$ & 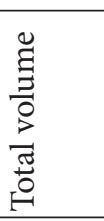 \\
\hline Rollers,km & & 248 & 246 & 459 & 288 & & & & & & & & 1241 \\
\hline Cross,km & 106 & 171 & 116 & 215 & 160 & 78 & 72 & 55 & 85 & 70 & 65 & 35 & 1228 \\
\hline Bike,km & 86 & 80 & & & & & & & & & & & 166 \\
\hline Skiing,km & & & & & & 277 & 480 & 286 & 442 & 349 & 335 & 256 & 2425 \\
\hline TOTAL km & 192 & 499 & 362 & 674 & 448 & 355 & 552 & 341 & 527 & 419 & 400 & 291 & 5060 \\
\hline
\end{tabular}

As seen from the figures in the table, the distribution of the cyclic training load was carried out by months of the annual cycle. The largest volume of cyclical load in the preparatory period were made in the month of August $2015(595 \mathrm{~km})$, and in the competitive period in the month of January $2016(507 \mathrm{~km})$. The figures in the next year of training respectively were $674 \mathrm{~km} 527$ and km.

In the annual cycle of training the general volume of cyclical load (OIN) is presented in kilometers (total), which is 4230 miles. This volume cyclic loading was performed by all members of the team biathlon-boys of the Moscow region sports season 2015-2016 academic year. The following annual cycle (2016-2017) the total amount of the cyclic load amounted to $5060 \mathrm{~km}$.

As follows from the data of the indicators tables 46,5-48.0 \% are for ski preparation of total cyclic load in the annual cycle of training.

The burden of movement on roller skis to the volume of running, walking and simulation, distributed approximately in equal shares.
In addition, it should be noted that the systematic increase in training load performed by Russian biathlon 18-19 age next year. This planning to increase the training load positively affects the achievement of high sports-technical results biathlon national team of the Moscow region.

The results of the competition period testified to the good sports-technical results which were shown by young athletes.

So, Tutmin E. and Sorokin, A., completed standard of master of sports of Russia in biathlon and Tutin E. took 3rd place at the world championship for young men in the composition of the relay of the Russian team. In addition, at the II youth Olympic games in Norway Tutin E. won 1 silver medal and 2 bronze ones (2015-2016)in the individual race. Zintsov $\mathrm{K}$. performed the standard of candidate master of sports of Russia in biathlon and successfully competed at the Central district championship and superiority of Russia among young men.

\section{Conclusions.}

1.In the annual cycle in 2017-2018 the general volume of cyclical load training means training on 
a monthly and annual cycle of training should be reviewed.

2. To increase the training volume of cyclical load in the preparatory period in such a facility, as cycling. 3. To sustain the concept of planning and distribution parameters of the training loads as a percentage in the annual cycle of training.

\section{References:}

Dunayev K. S. (2008) "Analysis of competitive activity as the factor of optimization of process of training of the Russian biathlonists for responsible starts", Theory and practice of physical culture. M...-№ 2. - P.40-43.

Dunayev K. S., Selifonov A. A., Baranova L. (2014), "Planning of training loads in junior biathlon national team of Russia in year cycle of preparation. The Olympic Games and modern society", Materials of the All-Russian scientific and practical conference with the international participation, October 30 -November 1, Malakhovka, P. 88-90.

Dunayev K. S., Selifonov A. A., Fedotov S. I. (2015) "Planning of training load in junior biathlon. The modern system of sports preparation in biathlon",Materials of the IV All-Russian scientific and practical conference. Omsk, p. 39-43.

Dunayev K.S., Aleksashin D.Y. (2013) "Conceptu- al aspects of Russian biathlon training for the Winter Olympic Games in Sochi in 2014.", The final collection of All-Russian scientific-practical conference. The final stage of preparation of sports national teams to XXII Olympic Winter Games 2014 in Sochi,,M.., P. 40-43.

Dunayev K. S., Kriventsov A. L. (2014) "Modern problems of the Russian biathlon. "The Olympic sport and sport for everybody».18 International scientific congress", Materials of the congress. October 14, 20142 vol., Almaty, , P. 155-159.

Farbey, V. V. , Dunayev K.S. (2011) "Experimental study of the influence of the orientation of the training process to increase the level of preparedness of athletes", scientific notes University. P. F. Lesgaft., №3 (73). P. 190-194.

Seyranov, S. G., Dunayev K.S. (2016) "Problems and the state of development of the Russian student biathlon", The modern system of sports training in biathlon. Materials of $\mathrm{V}$ all-Russian scientific-practical conference. by the general editorship of V. A. Aikin, N. With. Zagursky. Omsk.,P. 204-209.

Seyranov, S. G., Dunayev K.S. (2017) “Actual problems of the student biathlon", Innovation-Education-Sport : proceedings of the world winter of the FISU conference / education and science of the Republic of Kazakhstan ; the international University sports Federation ; Federation of student sport of the Republic of Kazakhstan ; Kazakh Academy of sport and tourism., Almaty,.P. 152155. 